\title{
FORMAÇÃO DE PROFESSORES DE INGLÊS PARA ABORDAGEM DE QUESTÕES ÉTNICO-RACIAIS: PRÁTICAS PLANEJADAS E PRÁTICAS MANIFESTAS
}

\author{
ENGLISH TEACHER TRAINING TO ADDRESS ETHNIC-RACIAL ISSUES: \\ PLANNED PRACTICES AND MANIFESTED PRACTICES
}

\author{
Joelma Silva Santos*
}

\begin{abstract}
RESUMO
Documentos oficiais relacionados à Lei 10639/03 dispõem orientações gerais para sua implementação nas instituições de ensino superior. Porém os cursos de formação de professores de inglês ainda carecem de fundamentos específicos e práticos para a abordagem do conteúdo da Lei no ensino deste idioma. Isso significa que muitos/as professores/as de inglês em exercício não se apropriaram de conhecimentos teórico-metodológicos para trabalharem questões raciais em suas aulas (FERREIRA, 2006). Este artigo consta da descrição de conteúdos, metodologia e teorizações derivadas das aulas de um curso de extensão sobre as questões étnico-raciais e culturas de matriz africana no ensino de inglês. Neste curso, estiveram envolvidos 8 professores/as de inglês atuantes na educação básica e superior de Salvador (BA), e teve a duração de $45 \mathrm{~h}$. Gradativamente, como uma contingência do grupo, parte das aulas voltou-se para o compartilhamento de narrativas de discriminação. O evento levou-me a constatação da importância da fala como mecanismo de consolação do sofrimento, assim como insumo fundamental para o redimensionamento das identidades sociais raciais dos/as docentes. Instaurou-se, assim, o momento bealing storytelling como parte metodologicamente necessária desta formação. A experiência não só ofereceu base teórica para os/as professores/as abordarem as questões sociais, históricas e culturais referentes ao negro quanto aguçou sua percepção para eventos cotidianos de racismo que já haviam assistido, escutado ou vivenciado dentro e fora da sala de aula. A identidade social racial do/a sujeito/a professor/a parece determinante da forma com a qual ele/ela compreende as questões étnico-raciais e de como se posicionam diante desses temas.

Palavras-chave: ensino de inglês; raça/etnia; formação de professores; bealing Storytelling.
\end{abstract}

\section{ABSTRACT}

Official documents related to Law 10.639/03 provide general guidelines for its implementation in higher education institutions. However, English teacher training courses still lack specific and practical foundations to address the law content in English teaching. It means that many English teachers do not use theoretical and methodological knowledge to work on racial issues in their classes (FERREIRA, 2006). This article shows the description of contents, methodology, and theories derived from a university extension project on ethnic-racial issues and African cultures in English teaching. The project involved 9 English teachers who work in elementary and higher education in Salvador (BA) and had a course load of 45 hours. Gradually, since the group demanded, part of the classes turned to be for sharing narratives of discrimination. The event made me realize the importance of speech as a mechanism to comfort the suffering, in addition to being a fundamental input for teachers recreating their social identity of race. Thus, we set a time for the healing storytelling as a methodologically necessary part of this training. The experience not only offered a theoretical basis for teachers to address social, historical, and cultural issues related to blacks but also sharpened their perception of the daily events of racism that they had already seen, heard, or experienced inside and outside the classroom. Teacher's social identity of race seems to be decisive for them to understand ethnic-racial issues and taking a position on these themes.

Keywords: English teaching; race/ethnicity; teacher training; healing Storytelling.

A Lei educacional n $n^{\circ}$ 10639/03 trouxe a obrigatoriedade do conteúdo de História e Cultura Afro-Brasileira e Africana em todas as disciplinas do currículo escolar de Ensino Fundamental e Médio nas diretrizes e bases da educação nacional (BRASIL, 2003). Mais tarde, foram elaborados a Resolução 01/2004 (BRASIL, 2004) e o Parecer CNE03/2004 (BRASIL, 2004), instrumentos oficiais que, além de regulamentarem o cumprimento da Lei, estendem amplamente as prerrogativas deste documento, inclusive apresentando orientações quanto às atribuições das Instituições de Ensino nesse cenário.

No artigo primeiro da Resolução 01/2004, são instituídas as Diretrizes Curriculares Nacionais para a Educação das Relações Étnico-raciais e para o Ensino de História e Cultura Afro-Brasileira e Africana (doravante refiro a estas diretrizes como Diretrizes Curriculares Raciais). O Parecer CNE03/2004, por sua vez, entre outros encaminhamentos, explicita algumas ações a serem empreendidas pelas Instituições de Ensino Superior que abrigam programas de

* Doutoranda no Programa de Pós-Graduação Língua e Cultura na Universidade Federal da Bahia (UFBA), Salvador, Bahia, Brasil. joelma. wx@gmail.com

Orcid: https://orcid.org/0000-0001-6862-8601 
formação inicial ou continuada de professores, dentre as quais, está a inclusão de temáticas e questões concernentes aos afrodescendentes no conteúdo das disciplinas e atividades curriculares. De acordo com o texto das Diretrizes Curriculares Raciais os/as educadores/as precisam reformular suas concepções e práticas de ensino no que se refere à população negra, maioria nas escolas públicas regulares.

Não ignoro que já existem muitas experiências registradas sobre a implementação das Diretrizes Curriculares Raciais, porém as ações desenvolvidas geralmente partem da iniciativa isolada e pontual de profissionais preocupados com a questão. Há mais casos de docentes que só souberam recentemente que o trabalho com a temática não deve estar restrito às matérias de História e Sociologia e outros/as que ainda se encontram em negação de fazê-lo até hoje. Parte deste alheamento se deve à carência de formação para tratarem destas questões a partir da apropriação teórica, das estratégias pedagógicas e da consciência racial necessárias para sentirem-se seguros/as diante da abordagem de temáticas tão sensíveis. Parece não haver um movimento sistemático para integrar as diretrizes aos cursos de formação de professores, o que impede a articulação do debate sobre raça com as especificidade de cada área de estudo. É importante registrar a urgência da revisão dos currículos universitários quanto à oferta de disciplinas. Em primeira instância, é necessário que as disciplinas voltadas para a temática sejam ofertadas e, sendo ofertadas, deem centralidade ao conteúdo raça/racismo, destoando da abordagem periférica ou em caráter optativo comuns nos currículos dos cursos de Letras atuais. Neste cenário, professores/as de inglês que não têm acesso aos poucos cursos de pós-graduação do país atentos a esta questão, a exemplo da linha Pluralidade, Identidade e Ensino da Universidade Estadual de Ponta Grossa (UEPG) e a linha e Racismo no ensino de Língua Estrangeira da Universidade Estadual de Santa Cruz (UESC), ou a atividades extensionistas como a que relato neste artigo, encontram-se desamparados há quase 20 anos, a contar do decreto da Lei 10.639/03.

Enquanto nos mantemos reivindicando revisão curricular e a formação de professores conforme indicam os documentos oficiais dispostos, apresento uma breve descrição de como se deu uma atividade de extensão voltada para o trabalho com questões étnico-raciais e culturas de matriz africana no ensino de inglês. O objetivo é demonstrar um exemplo de como o trabalho com a temática pode ser feito junto a professores/as de inglês, apontando alguns dos desafios e resultados positivos proporcionados pela experiência. Assim, discorro sobre 1) a conjuntura do curso, incluindo como foi estruturado, onde, número de participantes, objetivos, metodologia, produções dos cursistas entre outros aspectos; 2 ) uma prática manifesta pelo grupo e que se tornou uma metodologia integrante deste processo de formação, o bealing storytelling; 3) o perfil dos participantes, já atravessado por uma breve análise sobre as implicações da sua identidade social de raça em suas ações e posicionamentos ao longo do curso.

\section{OS MEIOS, OS FINS E AS CONTINUIDADES}

Os novos caminhos da Linguística Aplicada (LA) incluem a diversificação das metodologias de pesquisa. Em vez das pesquisas de cunho experimental de outrora, sobrepõem-se as pesquisas qualitativas orientadas pelo paradigma interpretativo que, por sua vez, prevê a construção do conhecimento a partir de leituras da realidade. Os trabalhos deste campo passam a ser orientados para a resolução de problemas manifestos por meio da língua em práticas sociais (MOITA LOPES, 1996). Há uma importância não só metodológica, mas política de garantir mudanças profundas no contexto e vida dos/as sujeitos/as sob investigação. A inserção de questões étnico-raciais e cultura negra nas aulas de inglês materializa bem a meta dos estudos em LA, afinal pressupõe a construção de saberes marcados sócio-historicamente, além da compreensão de fenômenos linguísticos associados ao mundo real, este que é invariavelmente racista.

Atenta a perspectiva de uma Linguística Aplicada politizada, encontrei a premissa da intervenção para mudanças na pesquisa-ação, isto é, intervir a partir de uma prática participante e engajada na solução do problema da escassez de formações voltadas para as questões étnico-raciais junto ao ensino de língua estrangeira na região. Como trabalhei com formação de professores/as, o método também contemplou meus objetivos no ponto em que orientou a relação entre o eu pesquisador/a e o/a outro/a objeto/sujeito/a de pesquisa sob a condição de sujeitos/as constituído sóciohistoricamente e, portanto, perpassados/as por implicações da estrutura social. Esta compreensão se torna fundamental quando se espera que a identidade social de raça dos/as participantes seja um elemento determinante da composição teórica da pesquisa, somados aos fenômenos manifestados no campo e à interpretação do/a pesquisador/a. 
No entanto, afastei-me do viés anglo-saxônico da pesquisa-ação, aquele que propõe um caráter meramente diagnóstico do/a pesquisador/a frente aos/às participantes da pesquisa (ELLIOT, 1989). Interessava-me mais trabalhar com uma proposta de alcance educativo, formativo, em que houvesse implicação do/as sujeitos/as envolvidos/as de maneira crítica e gradativamente mais autônoma. Tal abordagem enquadra-se melhor na perspectiva australiana de pesquisa-ação (CARR e KEMMIS, 1988) que explora a dimensão do currículo, da análise de programas e planejamento para avançar em direção ao desenvolvimento profissional dos/as sujeitos/as, minha meta principal. Ademais, no caso desta pesquisa, a abordagem também pode contribuir para a formulação de orientações que favoreçam práticas semelhantes e o desenvolvimento do tópico. Com sucesso, isso pode motivar a elaboração de políticas para o ensino das questões étnico-raciais nos cursos de graduação em Letras, contexto carente deste debate como já exposto aqui.

A pesquisa-ação requer um ciclo de procedimentos que se configura basicamente em quatro fases: a fase exploratória; a fase de planejamento da ação; a fase de implementação da intervenção e a fase avaliativa. Estas fases são melhor definidas a seguir. Vale enfatizar que todas as fases do processo foram iniciadas a partir da reflexão sobre a prática corrente ou a anterior, conforme ensina Tripp (2005). De acordo com o autor, a reflexão perpassa todo o ciclo desse tipo de pesquisa e é essencial tanto no planejamento, quanto na implementação e monitoramento das ações. Para fins de avaliação dos eventos ocorridos, a reflexão deve ser exercida ao final do processo também. Desse momento, podem decorrer novas demandas, até mesmo, a necessidade de repetição do circuito. Como se observa, a pesquisaação tem como característica uma densa atividade reflexiva, o que não é exclusivo desse tipo de investigação, porém, nesse método, certa complexidade se instaura porque a reflexão deve ser exercida sistematicamente por todos/as os/ as participantes do processo e isso deve impactar na configuração das etapas seguintes.

A partir destes parâmetros, iniciei o projeto de extensão Questões étnico-raciais e culturas de matriz africana no ensino de língua inglesa ${ }^{1}$ que foi inscrito no Sistema de Registro e Acompanhamento de Atividades de Extensão (SIATEX) da Pró-reitoria de extensão da Universidade Federal da Bahia e sediado no Núcleo Permanente de Pesquisa e Extensão em Letras (NUPEL/UFBA). O curso foi de natureza formativo-educacional, assim como tratou-se de uma ação eventual da universidade, pois não havia planos para abertura de outras turmas ou de outros cursos de mesmo teor. A carga horária foi de 48h, desmembradas em 16 aulas com a duração de 3 h ao longo de um semestre.

Entres os objetivos do curso, constavam a) fazer um levantamento quanto aos pré-requisitos teóricos do grupo acerca da temática raça, ou seja, investigar se já traziam saberes relacionados com o tema e como adquiriram; b) desenvolver um plano de curso que atendesse às demandas apresentadas pelos/as participantes quanto ao assunto; c) oportunizar debate extensivo da bibliografia selecionada. A bibliografia, por sua vez, foi integrada fundamentalmente por autores/ras negros/as; d) aplicar atividades que conduzissem os/as professores/as ao exercício dos conhecimentos adquiridos; e e) proporcionar momentos de autoavaliação e avaliação do processo para os/as participantes, a fim de que relatassem os efeitos da experiência na sua maneira de pensar as questões étnico-raciais.

Nos encontros iniciais, busquei identificar se e como se deu a formação pedagógica dos professores quanto à abordagem da temática raça dentro e/ou fora da universidade. Para tanto, apliquei questionários semiestruturados, recolhi narrativas autobiográficas, bem como registrei alguns depoimentos sobre suas experiências durante as aulas. Assim, se deu a fase exploratória, voltada para um levantamento das demandas dos/as professores/as. Registrei suas convicções quanto ao debate de raça e a maneira como tais convicções eram representadas, a fim de pensar na ação mais apropriada para atender à conjuntura. A seguir, na fase de planejamento da ação, elaborei um plano de curso com vistas a trazer contribuições para a questões previamente evidenciadas, levando em consideração o conteúdo das Diretrizes Curriculares Raciais; acepções advindas do Letramento Racial Crítico (FERREIRA, 2015); da Teoria Racial Crítica (LADSON-BILLINGS, 2006; FERREIRA, 2006; SOLÓRZANO e YOSSO, 2009) e pensando no ensino de línguas a partir de premissas da Pedagogia Crítica (FREIRE, 1996; PENNYCOOK, 1994; RAJAGOPALAN, 2003) também.

Os conceitos acima foram considerados para amparar as dimensões da formação de professores/as, conteúdos étnico-raciais e o ensino de língua inglesa no plano de ação respectivamente. Adotei os fundamentos do Letramento Racial Crítico para subsidiar a formação de professores/as quanto à capacitação para abordarem temáticas raciais pedagogicamente. Esse processo requer a compreensão do quanto a raça influencia nas experiências sociais dos/ as sujeitos/as de modo geral e que esta variável é instrumento de regulação social, de controle, opera em todas as

1. Este curso de extensão tratou-se da parte de campo da pesquisa de doutorado, então, intitulada Contribuições teórico-metodológicas para abordar "raça" no ensino de inglês: incursão rumo às demandas dos professores orientada pela Profa. Dra. Denise Scheyerl. 
instâncias, inclusive na escola. Significa dizer que trabalhar sob as premissas do Letramento Racial Crítico junto a professores/as de inglês já invalida prontamente a crença de que não é importante discutir questões raciais nas aulas desta língua. O conceito também ajuda a pensar em como lidar com a branquitude, o que favorece a construção de estratégias para intervir na educação racial de estudantes não-negros/as e no entendimento de que o debate racial deve envolver todas as pessoas, motivando ações práticas em todos os setores sociais.

Com vistas a contemplar os conteúdos propostos pelas Diretrizes Curriculares Raciais, encontrei na Teoria Racial Crítica (LADSON-BILLINGS, 2009) insumo teórico para embasar o trabalho com as questões étnico-raciais no contexto da educação. O argumento principal neste sentido é que somente através do viés racial seja possível compreender os obstáculos educacionais enfrentados por negros. Diante disso, a Teoria Racial Crítica preconiza a elaboração de estratégias através das quais tais obstáculos possam ser resistidos e superados. Para tanto, deve-se considerar parâmetros como: 1) o racismo está presente em todas as sociedades e define as experiências individuais das pessoas; 2) é necessário problematizar ideias como objetividade, meritocracia, neutralidade racial, igualdade racial e invisibilidade da cor; 3) torna-se indispensável comprometer-se com a justiça social e lutar contra as desigualdades pautadas em raça, gênero e classe; e 5) reconhecer a validade do conhecimento produzido a partir das experiências de vida do negro, pois ele torna-se fundamental para a compreensão, análise e ensino sobre subordinação racial.

Quanto ao ensino-aprendizagem de inglês, defendo que ele extrapole o desenvolvimento de habilidades linguísticas. Importa a adoção de procedimentos que não só promovam a convivência democrática entre culturas, mas também estabeleçam reflexões acerca de identidades sociais locais diante do global, considerando corpos, saberes específicos, linguagens e relações de poder pautadas, sobretudo, na variável raça neste caso. Por isso é preciso pensar na pedagogização crítica (FREIRE, 1996; PENNYCOOK, 1994; RAJAGOPALAN, 2003) do professor de línguas, considerar a formação de profissionais capazes de questionar a hegemonia do inglês e a problematizar as relações de poder político e econômico enredadas na configuração dessa língua no mundo. Deste modo, este/esta educador/a pode evitar a ideia de universalização de comportamentos, valores e atitudes tão presente nas salas de aula de línguas.

Voltando às etapas da pesquisa, no estágio de implementação da intervenção, se deram as aulas do curso nas quais aconteceram discussões extensas sobre a bibliografia selecionada. Entre os temas debatidos, tivemos as terminologias do campo racial, racismo estrutural, representação do negro no livro didático, miscigenação, identidade negra, estética negra, genocídio da juventude negra e religiões de matriz africana. Faltou tempo para que falássemos com ênfase sobre feminismo negro, ações afirmativas, relacionamentos interraciais e apropriação cultural, embora estes assuntos tenham surgido de maneira transversal nos debates e tenhamos conversado sobre suas nuances. Em todas as aulas, distribuí apostilas que elaborei com questões para reflexão sobre o tema e propostas de aplicação dos conteúdos debatidos no ensino de inglês.

$\mathrm{Na}$ etapa final, aconteceu um seminário temático por meio do qual planejei contemplar a temática African cultures. A proposta foi que os/as cursistas apresentassem um panorama cultural de países africanos em que o inglês é língua oficial, enfatizando aspectos que pudessem parecer incomuns e familiares a nós, ao mesmo em que propusessem uma forma de abordar o mesmo conteúdo em aulas de inglês. Nestas apresentações, conhecemos possibilidades de explorar vestuário, comida, hábitos, atividades de lazer, lugares, religiões, personalidades, política entre outras dimensões culturais de países africanos. Também foi possível conhecer de que maneira os/as professores/ as acionavam os conhecimentos adquiridos. A avaliação dos seminários foi feita coletivamente. A diversidade de estratégias e ferramentas de ensino utilizadas para trabalhar os temas foi o ponto sinalizado como o mais positivo pelo grupo. Como ponto negativo, percebemos que o tempo curto levou à exposição superficial de temáticas que requeriam mais atenção, tal como a influência da política e religião no estilo de vida de alguns povos. Entendemos que o tema African Cultures não podia ser trabalhado devidamente, sem trivialidade, no tempo que dispomos.

A fase de avaliação do processo foi desenvolvida nos dois encontros finais. Além de analisarem o curso, os/ as professores/as se autoavaliarem também. Para tanto, utilizei sessões reflexivas sob a compreensão de Grimmet (1988). O autor ensina que as sessões de reflexão crítica promovem a identificação de novas possibilidades de agir a partir da reconstrução da experiência. Assim, os/as docentes podem redimensionar a maneira como entendem as situações, o meio educacional em que atuam, o ensino de modo geral e a si mesmos/as, apartando-se de distorções sociais, políticas e culturais. Entre as questões sugeridas para este momento, estiveram: 1) de onde procedem as ideias que eu incorporava em minha prática de ensino no que tange à raça/etnia? 2) Como me apropriei delas? A que interesses servem? Que relações de poder estão imbricadas nestas práticas (ou ausência delas)? Como estas ideias 
influenciam o meu relacionamento com os estudantes? 3) Com base no que aprendi no curso, como posso trabalhar de forma diferente?

Os dados produzidos nesta fase foram extensos e, portanto, servem de corpora para outro trabalho. Para os fins e dimensão deste artigo, lembro que coube a descrição da atividade de extensão na sua estrutura, conteúdos e metodologia.

Informo que plano de curso também previa que os/as docentes elaborassem uma atividade em inglês perpassado por um conteúdo racial. Esta atividade deveria ser apresentada e avaliada pelo grupo, o que proporcionaria outra oportunidade de avaliação dos impactos da formação nos/as cursistas, assim como mais oportunidades de aprendizado. Embora isso não tenha sido viável dentro do tempo previsto para o curso, me mantive em contato com os/as participantes com o plano de construirmos um livro de atividades posteriormente. Entendi que a fase de avaliação da pesquisa seguiria e poderia identificar novas formas de intervenção. A rigor, as informações produzidas no estágio de avaliação devem mesmo amparar a implementação de ações mais condizentes com o público da pesquisa (THIOLLENT, 1986), neste caso, não só os/as professores de inglês envolvidos no projeto. Por isso planejei propor uma ação que tivesse implicações mais amplas e em outros contextos também. Um livro de atividades poderia ser este elemento mais concreto, um resultado passível de alcançar outros/as docentes, oferecendo conceitos, recomendações e material contundente para o trabalho com as questões étnico-raciais em aulas de inglês diversas. Inclusive, através das suas atividades, poderia verificar como os/as participantes da pesquisa se apropriariam teoricamente dos temas; como promoveriam a desconstrução de estereótipos; que proposições fariam em prol do empoderamento de estudantes; e de que maneira problematizariam os conteúdos.

Quatro meses após o fim do curso, iniciamos a elaboração do projeto Black Matters Matter. Tínhamos encontros quinzenais ou semanais, conforme necessidade, por meio de aplicativos de reunião. Primeiramente, montamos uma proposta de plano de aula e decidimos o que eles deveriam conter, a saber: informações quanto às séries escolares para quais pensamos a aula; tópico do campo racial abordado; habilidades e conteúdos linguísticos a serem acionados; objetivos atitudinais; recursos necessários para a efetivação da aula; sugestões de leitura para a sustentação teórica do trabalho e procedimentos sugeridos para a aplicação das atividades. Além da sessão bealing storytelling sobre a qual explano ainda neste artigo.

Propus que os/as cursistas utilizassem os temas livremente e produzissem duas atividades ao menos. Após seis semanas, iniciamos as reuniões para avaliarmos o material produzido, tínhamos um total de 40 planos de aulas e atividades. O trabalho de avaliação destes planos e atividades foi meticuloso. Inúmeras vezes, interrompemos o processo para discutir detalhes que podiam resvalar em generalizações, manutenção de estereótipos ou na trivialização de questões complexas. Esses encontros levaram a formação para outro nível e, assim como o conteúdo das sessões reflexivas, serão escopo para trabalho posterior. Ao final, tínhamos o livro dividido em 5 blocos; 1) African diaspora and cultures; 2) Black Body and Symbols; 3) Black Personalities; 4) Black Visibility in mass media; 5) Racism and Anti-racism. ${ }^{2}$

No bloco African Diaspora and Cultures, estão elencadas as atividades construídas com o objetivo de problematizar e recriar o lugar que África ocupa no imaginário social. Os textos, as imagens e as tarefas reviram o que se sabe sobre o continente-mundo, trazendo informações sobre as populações africanas e afrodescendentes espalhadas pelo planeta nos dias atuais. Este bloco certamente aciona o conceito de diáspora negra introduzido por Gilroy (2001) quando aponta a existência de uma articulação entre as manifestações culturais e vivências de origem africana à revelia da liquidez cultural própria do cenário mundial pós-globalização.

O bloco Black body and Symbols traz atividades voltadas para o trabalho com os significantes e significados do corpo negro, com atenção às relações de poder inerentes a leitura social deste corpo. Trata da identidade negra através dos valores traduzidos pela estética, elemento fundamental de tradição e resistência frente a uma sociedade erguida sobre padrões de beleza brancos e eurocentrados. Sabemos que esta expressão da identidade negra cresceu sensivelmente nos últimos tempos. Cabelos crespos naturais, turbantes, colares, estampas africanas já não causam tanto estranhamento como outrora. Porém, infelizmente, não se esgotam os estigmas e discursos preconceituosos acerca do fenótipo de afrodescendentes. Em vista disso, para além da afirmação positiva das diferenças estéticas do/a negro/a, marcamos a potência e dimensão ancestral de sua beleza nestas atividades.

2. 1) Diáspora e culturas africanas; 2) Corpo negro e símbolos; 3) Personalidades negras; 4) Visibilidade negra na mídia de massa 5 ) Racismo e antirracismo. 
Na seção Black Personalities, apresentamos atividades que projetam a trajetória de personalidades negras nacionais e internacionais, a fim de suscitar imagens, vozes e sentidos de homens e mulheres que têm tecido a história do povo negro ao longo dos tempos. São referências indispensáveis para remover estigmas introjetados pelo racismo, ao mesmo tempo em que estabelecem novos parâmetros para construção de subjetividades. Neste sentido, assinalamos a contribuição desses/as sujeitos/as em diferentes áreas do conhecimento, tanto nas ciências exatas e humanas quanto no esporte e em outros setores sociais. A proposta foi dar ênfase à agência de negros e negras para o avanço de setores como a economia, desenvolvimento social e cultura do Brasil e do mundo, tal qual previsto pelas Diretrizes Curriculares Raciais.

As atividades elencadas na seção Black Visibility in mass media trazem para o foco da cena negros e negras nos meios de divulgação cultural e artística como a imprensa, televisão, cinema, mídia impressa e meios eletrônicos e telemáticos. Por meio destas atividades, buscamos fazer ver e (re)conhecer outras referências, outras representações e outras narrativas sob o protagonismo de artistas negros/negras. Também, problematizamos as representações tradicionais de negritude através de exemplos práticos que ilustram os mecanismos racistas que têm sido utilizados para retratar o/a negro/a. Não dispensamos a apresentação de estratégias para a compreensão destes mecanismos e desmistificação da imagem branca como ideal, tão divulgada nesses meios.

Com as atividades do bloco Racism and Anti-racism, as questões raciais podem ser discutidas sob um viés mais literal. Desta vez, o tema racismo se apresenta de maneira direta, porque exploramos o conceito, ou seja, a crença na existência de pessoas inferiores por natureza, como condição inata. Esta construção que é meramente ideológica, mas impactou na formação das sociedades em níveis estruturais, conduz a existência de povos de matriz africana à subalternidade de maneira sistemática, com raras possibilidades de escape. Por isso propomos a reflexão sobre esta ideia historicamente retroalimentada, a partir das mensagens pouco subliminares dos meios de comunicação, das regras e procedimentos das instituições, da aparência das pessoas em lugares de status e poder, dos valores aprendidos no interior das famílias, entre amigos/as, na escola, nas ruas etc. Em resumo, estas atividades ensinam que o racismo opera em toda parte, e na maioria das relações sociais. No entanto, a proposta não se encerra na constatação do racismo. Pensamos em interrogar discursos e comportamentos, e juntamente empreender ações antirracistas, incentivando a ruptura de silêncios e a recusa da neutralidade diante de situações racistas.

O conteúdo deste livro comprova mais um dos pressupostos do Letramento Racial Crítico e Teoria Racial Crítica, isto é, a importância de produzir conhecimento que problematize os instrumentos de letramento tradicionais de uso da língua. É possível ensinar inglês letrando por meio de textos/enunciados que comuniquem informações de cunho ideológico essenciais para a formação cidadã, assim o fizemos.

Para além dos efeitos aparentes que o curso suscitou nos/as educadores/as, tais como a apropriação teórica sobre o campo racial para elaboração de material didático, é importante levar em conta implicações adicionais. Ainda com base na perspectiva do Letramento Racial Crítico, quando sinaliza que a compreensão sobre raça e racismo traz impactos não só na identidade social de raça quanto nas relações sociais em todas as esferas da vida (FERREIRA, 2015), destaco outros aspectos importantes detectados durante o processo. Pude verificar nas falas dos/as professores/ as, uma maior predisposição para problematizar as práticas anteriores à formação; mais consciência para identificar e dar nomes precisos aos problemas relacionados à raça, o que por sua vez, os/as motivou a buscar soluções ou reagir mais politicamente em seu entorno; e maior interesse em desenvolver estudos aprofundados sobre os conceitos e teorias vistos, a fim de obterem mais suporte teórico para aprimorar as suas práticas.

\section{SOBRE O HEALING STORYTELLING: UMA METODOLOGIA INSURGENTE}

A metodologia para o desenvolvimento das aulas parecia bem simples. Faríamos o debate dos textos teóricos selecionados e, a seguir, pensaríamos em possibilidades de abordar a temática de maneira didática e pertinente junto aos/às estudantes nas aulas de inglês. Contudo, ao longo dos encontros, as demandas de ordem afetiva e psicológica relacionadas às experiências de racismo dos/as cursistas sobrepuseram a proposta inicial. O compartilhamento das suas histórias e dores ou histórias de conhecidos/as se repetia naturalmente em todas as aulas.

Os encontros passaram a ter a tônica das rodas de conversa, hoje, reconhecidamente valiosas para o compartilhamento de narrativas de discriminação, o que reforça a importância da fala como mecanismo de consolação e mediação do sofrimento. Porém desvendar o olhar custava-lhes reflexões sofridas. As lembranças, preferências, 
atitudes e ações passadas suas e de outras pessoas eram escrutinadas, revelando o óbvio: o racismo de que tanto se fala, às vezes, pouco se sabe, e ele não se restringe a manifestações individuais deste/a ou daquele/a sujeito/a. Numa turma com seis negros/as entre oito cursistas, o racismo como engenharia que estrutura todas as relações sociais (ALMEIDA, 2019; FANON, 2008) havia marcado a maioria daquelas vidas indistintamente.

Não raro, as narrativas eram entrecortadas por pranto, emoção trazida junto com as histórias de discriminação que viveram ou conheciam. O planejamento que, via de regra, mirava o cumprimento dos objetivos conceituais do curso sucumbia às demandas identitárias dos/as sujeitos/as. As teorias perdiam lugar para as vivências reais. $\mathrm{Ou}$, de outro ponto de vista, as teorias permitiram que os/as docentes reconhecessem fatos racistas previamente configurados como circunstâncias naturais. Tornou-se difícil moderar esses momentos. Na busca por orientações para lidar com o fenômeno, encontrei a pedagogia de hooks (2010) ensinando a relevância das experiências compartilhadas como ferramenta para melhorar a aprendizado em comunidade

What becomes evident is that in the global community life is sustained by stories. A powerful way we connect with a diverse world is by listening to the different stories we are told. These stories are a way of knowing. Therefore, they contain both power and the art of possibility. $^{3}$ (hooks, 2010, p. 53)

Contudo, hooks (2010) também sinaliza que o/a professor/as precisa garantir que as leituras propostas sejam cumpridas. Elas eram, mas em menor velocidade. Levava tempo finalizar um bloco temático. Como pesquisadora e participante do processo, não encobri a angústia que o atraso no programa me trazia. Lamentava pelos conteúdos que fatalmente seriam subtraídos do planejamento. Porém não tardei a ser convencida pelas contingências do contexto. Não podia desconsiderar que estava revirando instâncias da consciência racial dos/as cursistas, bem como a maneira com que se relacionavam com suas memórias e a própria existência. Ao mesmo tempo, tratava-se de um grupo de professores/as de línguas, habituados/as a utilizarem a linguagem para comparar, relacionar e discutir conteúdos como atividade profissional. A disposição para contar bistórias refletia também a grande bagagem daquelas/as educadores/as linguísticos atentos aos efeitos pedagógicos e positivos de oferecer e receber feedbacks.

A densidade dos diálogos me conduziram a validar ainda mais a dimensão humana, social e histórica daqueles/ as sujeitos/as. Mais ainda, comecei a visualizar o potencial científico das informações compartilhadas. As experiências comunicavam situações de invisibilidade política nos ambientes de trabalho, dificuldades de acessar espaços elitizados, humilhações sociais em ambientes coletivos de sua própria moradia, a exemplo de garagem e elevadores de prédios ou humilhações quanto a estereotipias relacionadas a seus corpos, só para citar alguns eventos. Estas violências materiais e simbólicas pautadas em valores e crenças da branquitude eram transferidas dos textos acadêmicos para as falas dos/as participantes. Estruturas ideológicas, concepções de mundo e os sentidos próprios do grupos sociais de raça a que pertenciam se apresentavam como dados contundentes. Então, comprovei que o que se encontra na esfera do pessoal é político e vale tanto quanto informação factual, conforme hooks (2010) assegura.

Convencida de que havia uma intensa produção de conhecimento ali, estabeleci o momento bealing storytelling, que se tornou parte fundamental do que passei a considerar o mais genuíno fazer pedagógico racialmente e politicamente engajado. Este processo se transformou em proposta metodológica do Black Matters Matter também. Orientamos que os/as docentes em contato com o livro utilizem o bealing storytelling como fechamento das atividades. Neste material, há uma seção que traz perguntas, reflexões ou narrativas curtas que devem levar os/as estudantes a pensarem sobre o tema da atividade a partir de um ponto de vista mais particular, relacionando a temática com as suas experiências ou experiências de pessoas do seu círculo afetivo. A intenção é motivá-los/as a resgatarem lembranças, atitudes, preferências, discursos e ações passadas que possam revelar histórias de discriminação que viveram ou conhecem. Este momento pode tornar possível a releitura de fatos racistas previamente entendidos como circunstâncias naturais, tal qual aconteceu no curso de extensão do qual tratamos aqui. Pode, também, tornar os/as estudantes atentos/as às opressões vividas por si e pelos/as colegas.

Retomando os objetivos propostos neste trabalho, apresento os perfis dos/as professores/as cursistas na próxima seção, dando destaque a informações sobre sua identidade social de raça. Tracei estes perfis a partir de dados retirados dos questionários aplicados no início do curso, áudios de aulas, sessões reflexivas e registros em meu diário de bordo.

3. O que se torna evidente é que a vida na comunidade global é sustentada por histórias. Uma maneira poderosa de nos conectar com a diversidade do mundo é ouvindo as diferentes histórias que nos contam. Estas histórias são um caminho para saber. Portanto, elas contêm ambos: poder e a arte da possibilidade. (tradução minha) 


\section{RAINHAS E REIS AFRICANAS/OS DO ENSINO DE INGLÊS: PERFIL DOS/AS SUJEITO/AS PARTICIPANTES}

Antes de apresentar os perfis das rainhas e reis desta investigação, importa trazer reflexões acerca da instância identidade social de raça que, neste trabalho, compreendo como o mesmo que identidade étnico-racial.

De acordo com D’Adesk (2005), a formação da identidade étnico-racial, sendo ela uma identidade coletiva, é algo para além da noção de pertencimento, está mais ligada ao sentimento de pertencimento. $\mathrm{O}$ autor estabelece uma distinção interessante entre estar condicionado a compor um determinado grupo por circunstâncias externas (pertencimento) e se identificar com as características distintivas que definem o grupo socialmente (sentimento de pertencimento). Ferreira (2004, p.67) ratifica o conceito ao destacar que o aspecto racial da identidade diz respeito à "qualidade de relação, ao grau de compromisso ou ao modo como a pessoa se identifica com seu grupo racial".

As identidades étnico-raciais constroem-se atravessadas pela idealização do branco como parâmetro. Essa condição resulta de discursos legitimados ao longo do século XIX, quando a Europa, sob a égide da superioridade científica, apropria-se da prerrogativa de subordinar países e povos da periferia mundial. Para além de eleger os níveis estruturais e culturais das sociedades, a lógica eurocêntrica incide na existência dos povos. Povos não europeus são arremessados ao outro lado do abismo, onde supostamente estariam os portadores de formas e comportamentos repugnantes pertencentes às raças inscritas como inferiores, a exemplo dos negros africanos. $O$ europeu idealizou um Outro a partir de si, como Bento (2002) bem sintetiza e, nele, projetou características negativas diversas que engendram mecanismos de inferiorização e desumanização por séculos. Essas crenças e valores são amplamente assimilados pelo imaginário coletivo e tornam-se nascedouro das identidades étnico-raciais.

No Brasil, o principal insumo para estruturação das identidades advém de aspectos fenotípicos, características físicas aparentes, como cor de pele, textura do cabelo, nariz, boca e estética corporal. As diferenças são marcadas por traços diacríticos como pele escura versus pele clara, cabelo crespo versus cabelo liso etc., enquanto as relações de poder atreladas a essas diferenças são implantações europeias. Em linhas gerais, de um lado, tem-se o grupo étnico-racial negro relacionado a estereótipos e estigmas tais como, pobreza, maldade, incompetência, entre outras imagens negativas. De outro, encontra-se o grupo étnico-racial branco ao qual está associada uma série de significados positivos, a exemplo de superioridade moral e intelectual. Como consequência, o indivíduo negro pode internalizar representações inferiorizadas, aprender a desvalorizar seu grupo racial e dissociar-se de referências negras, rejeitando a si próprio e semelhantes (SILVA, 2001). O indivíduo branco, por sua vez, tende a naturalizar ideias de superioridade, e, ao usufruir de vantagens e privilégios estruturais, desonera-se dos conflitos raciais, mantendo-se no lugar da neutralidade e do silêncio perante as desigualdades sociais (BENTO, 2002).

Diante destas as explanações, reitero que trago as informações dispostas nesta seção com o propósito de demonstrar como propriedades das identidades étnico-raciais dos professores sob investigação se manifestaram em suas posturas frente à abordagem das questões étnico-raciais ao longo das aulas e como demandas individuais reverberaram na dinâmica do coletivo. Isto posto, apresento um breve perfil dos/as docentes participantes a seguir.

O grupo constava de apenas dois professores homens que identifico como Osei Tutu e Akbaenaton. Ambos jovens negros que atuam na educação infantil em escolas privadas da cidade. Akbaenaton era recém-graduado. Fez o curso de Letras em uma universidade privada por meio de uma bolsa social ofertada pela própria instituição. De origem humilde, morador de bairro periférico, homossexual, candomblecista e pardo, muitas vezes, narrou seus conflitos de identidade em função do seu tom de pele mais claro que contrastam com traços negroides irrefutáveis- cabelo crespo, nariz largo, lábios grossos. Ao longo do curso, suas narrativas ilustraram os efeitos da miscigenação na mentalidade do/a brasileiro/a regular, sendo mote para discussões acerca da ideologia do branqueamento e da fragilidade da ideia de invisibilidade da cor, por exemplo. Seu tom de pele era tomado como referência para ilustrar eventos com sujeitos/as das histórias dos/as colegas também. Geralmente, histórias que retratavam a propriedade de o/a pardo transitar entre identidades sociais de raça a depender do que o contexto impõe ou do que lhe convém. No grupo, Akhaenaton foi carinhosamente alcunhado de afro bege.

Osei Tutu estava finalizando o curso de Letras em uma universidade pública. Também de origem humilde e morador de um dos bairros mais afastados do centro da cidade, Osei Tutu frequentemente sinalizava sua dificuldade para concluir a graduação em função de questões de ordem afetiva e psicológica. Em suas narrativas, destacaramse as dores que sofreu por ser negro e por assumir a homossexualidade frente a uma família de base cristã. Os constrangimentos relatados foram vividos no âmbito da igreja, de locais de trabalho, até da sala de aula, neste caso, composta por crianças. Suas histórias traziam, com relevo, as marcas de opressão provocadas por sua raça, sexualidade 
e origem social, demonstrando a importância de acionarmos o conceito da interseccionalidade (CRENSHAW, 1991) para pensar as experiências sociais dos/as sujeitos/as. Não duvidada que as dificuldades acadêmicas e outras vulnerabilidades de Osei Tutu pudessem ter relação com as opressões decorrentes do racismo, capitalismo e cisheteropatriarcado articulados nos setores sociais. Ele declarava que as aulas do curso eram revigorantes e um espaço onde se sentia à vontade e acolhido.

Ainda pensando sobre interseccionalidade, informo que a turma constava de seis mulheres heterossexuais, três delas se autodeclararam negras, duas pardas e uma branca. Assim sendo, a turma do curso voltado para relações étnico-raciais e cultura negra no ensino de inglês era formada basicamente por mulheres negras. Interessante observar que o curso de Letras parece ser eminentemente feminino mesmo. Ao longo de minha formação, em todas as turmas em que estudei, mulheres eram a maioria. No quadro docente das universidades, este perfil parece se repetir. Provavelmente, isso explique a presença marcante de mulheres nesta formação também. No entanto, resta problematizar porque apenas uma pessoa branca se dispôs a participar de um curso com esta temática. Recomendo este aspecto para reflexão e sigo com a apresentação das sujeitas da investigação.

Nzinga era a cursista com o segundo maior tempo de formação e docência do grupo, quase 30 anos de atuação em escolas públicas, privadas, em cursos de idioma e de formação de professores. Seu nome e trajetória são conhecidos pela maioria dos/as profissionais de ensino de inglês da região, e a presença dela na turma agregou o conhecimento e a lucidez que só a experiência garante. Embora já colecionasse inúmeros certificados de cursos sobre metodologias e técnicas de ensino de inglês e, ao contrário do que se pudesse esperar de alguém finalizando a carreira, Nzinga, assídua e dedicada, sempre se mostrou disposta a aprender. Segundo ela, faltava-lhe a vivência de uma formação sobre questões raciais, assunto que lhe era caro. Nzinga contou muito das suas práticas abordando tópicos como Identidade Negra em suas aulas na escola pública, de forma intuitiva, como denominava. O curso lhe inquietava e ela ansiava por aplicar imediatamente os conhecimentos adquiridos. Os relatos da sua mobilização no ambiente de trabalho não tardaram. Nzinga tinha pressa em desenvolver ações e ter resultados.

Kabina é uma mulher madura, também com larga experiência na rede pública e privada. Ela chamou atenção para um dos problemas de trabalhar nestes contextos: em um cenário, sente-se descontente por não contar com mais recursos para atender às expectativas de estudantes carentes, mas empenhados/as; no outro, frustra-se ao lidar com alunos/as que esnobam as aulas de inglês por contarem com o privilégio dos cursos livres. Kahina se considera parda, embora possa ser facilmente entendida como branca a partir dos parâmetros sociais brasileiros de leitura de cor. Prova disso apresenta-se quando declara não perceber impacto das questões raciais em sua vida, o que justifica alegando viver entre negro/as em várias esferas. Talvez, o fato de Kahina ser candomblecista e profundamente ligada a fundamentos de matriz africana explique sua dificuldade de enxergar seu corpo como não-negro. Durante o curso, algumas vezes, o conflito da identificação racial dela se tornou tema. Triste constatar que a conexão ancestral de Kahina com o povo negro não altere a infalibilidade do racismo de base fenotípica.

A jovem senhora Hatshepsut é formada em Letras, ensina inglês, mas não oficialmente. Com longa vivência em localidade germânica, através dela, conhecemos bastante dos prazeres e dissabores de ser uma professora negra de alemão em contexto estrangeiro e na Bahia. Invariavelmente, suas extensas falas traziam informação de experiências raciais não só suas, histórias de outras pessoas também eram rememoradas para ilustrar situações que lhe causavam indignação. De maneira mais recorrente, ouvimos sobre uma escola estrangeira de educação infantil, sobre um grupo de pesquisa em língua, assim como sobre suas intervenções polêmicas em reuniões de pais e mestres, em assembleias como representante estudantil e em outras comissões. Entre a militância vigorosa e a utopia, a postura problematizadora de Hatshepsut convocava interlocuções estratégicas com instâncias que garantissem soluções para qualquer problema posto. No curso, ela buscava explorar perspectivas teórico-metodológicas para pensar as questões étnico-raciais no ensino-aprendizagem de alemão, temática de sua pesquisa de doutorado.

Nefertiti tem mais de duas décadas de docência em escolas de diferentes níveis e cursos de idiomas, além de ter atuado em cargos de coordenação pedagógica. Tem formações nacionais e estrangeiras no ensino de inglês, é doutora em Literatura, porém sua instrução extrapola redomas disciplinares. Sua história estampa bem os empecilhos sociais que costumam obstruir a vida da maioria das mulheres negras. No entanto, a raça, o gênero e a origem pobre não foram impedimento para que Nefertiti alcançasse cada um dos objetivos acadêmicos e profissionais que traçou para si. Sua determinação e conquistas nunca foram informadas por ela. Nas escassas narrativas, entendemos seu compromisso de incentivar o sucesso de outro/as membros/as e setores da comunidade negra. $\mathrm{O}$ som de sua voz não era habitual. Durante o curso, trazia consigo um semblante sério, sem sisudez. Parecia refletir sobre o que acontecia 
todo tempo. Suas expressões só alteravam quando declaravam algo com que parecia concordar, sua opinião havia encontrado um/a mensageiro/a. Às vezes, não se trata de não ter voz, trata-se de compactuar e sentir-se representada pelas dores dos/as outros/as. Mantinha-se na escuta.

Amina também ergueu duas décadas de carreira como professora de inglês em escolas públicas e privadas e orgulha-se muito de sua escolha profissional. Em relato escrito, Amina declara nunca ter notado atitudes racistas direcionadas a si, embora cite uma situação discriminatória vivida na infância em seguida, esta lembrança reivindicou presença. Possivelmente, Amina tenha naturalizado opressões por muito tempo. Inclusive a ausência de corpos semelhantes ao seu no primeiro curso de inglês ou nos locais onde transitou após ascensão social. Pode, ainda, ter permitido que seu declarado complexo de inferioridade de outrora perturbasse a interpretação mais acertada de suas experiências racializadas. Amina confessou ter se emocionado ao encontrar uma professora negra como ministrante do curso. Cada aula, parecia revelar mais do mundo real para ela. A leitura mudou! Mostrava-se decepcionada por não o ter problematizado antes, porém entusiasmada por ainda ter tempo para fazer a sua parte. Amina deveria saber que, como mulher negra e educadora, falar em fazer a sua parte torna-se pleonasmo.

Cleópatra tem apenas seis anos de licenciada em Letras, mas sua experiência docente já agrega escolas, curso de idioma e universidade. A priori, ensinar inglês foi uma alternativa para a impossibilidade de atuar como atriz, sua formação primeira. Já adulta, o comentário racista de um amigo branco a indignou muito, despertando sua atenção para perversidade do racismo dos bons. Tornou-se vigilante. A única cursista a se declarar branca, abandonou o parda, racializou seu corpo. Atribuía parte de sua conscientização racial à paixão pela literatura negra trabalhada por professoras negras de Letras. No curso, sua participação era intencionalmente passiva. Queria aprender com quem julgava ter a ensinar. Uma vez, relatou o desconforto de ouvir as experiências de racismo dos/as colegas, enquanto constatava a extensão de seus privilégios. Cleópatra sabe que não pode impedir todas as benesses que a cor lhe garante, mas seu discurso e conduta fazem crer numa branquitude crítica tangível. Hoje, seus estudos de mestrado conferem o lugar de tema ao branco. Caminho que poucos/as têm coragem de percorrer.

Neste ponto, cabe explorar como esses/as sujeitos/as se aproximam e se afastam em relação aos seus traços identitários, tendo em vista os estágios de construção da identidade afrodescendente, que serão confrontados com o perfil dos/as cursistas negros/as (FERREIRA, 2004), e estudos sobre a identidade racial branca e branquitude associados às cursistas socialmente brancas.

O comportamento manifesto por Akhaenaton e Osei Tutu e Amina permitiu observar a grande influência do debate racial e do convívio com outros/as professores/as negros/as no seu processo de construção identitária. No caso de Akhaenaton, ao contrário da dificuldade inicial de lidar com a oscilação da leitura de sua cor/raça pelas pessoas, ele parecia mais certo do seu pertencimento ao grupo étnico-racial negro, mais ainda do quanto a situação do pardo no Brasil está atrelada a um processo histórico de embranquecimento ideológico e fenotípico da população. Dentro da perspectiva dos estágios para a construção da identidade afrodescendente de Ferreira (2004), Akhaenaton parece estar transitando entre o estágio de submissão: fase em que o indivíduo negro está inconscientemente imerso nos valores da cultura branca dominante, aceita e se submete a eles; e o estágio de impacto: momento em que o sujeito tem experiências desestruturantes que o levam a um choque de valores e a revisar as referências que traz enraizadas sobre o universo branco. Então, em vez de se manter numa posição passiva sobre si, assimilando valores do grupo branco e se permitindo classificar de acordo com o grau de aceitação de cada contexto ao seu corpo, Akhaenaton demonstra uma tomada de consciência sobre a ineficácia destes valores na garantia de benefícios reais para ele, tanto materiais quanto psicológicos. Ele passa a se posicionar como negro e sedimenta o sentimento de pertencimento a este grupo. Não se trata mais de ser considerado branco às vezes, mas de perceber que as limitações do seu trânsito social, bem como suas dores se relacionam mais com aquelas das pessoas que compõem o grupo étnico-racial negro, a identificação se tornou inevitável.

As opressões que operam sobre a trajetória de Osei Tutu são de cunho racial, sexual e religioso e o instalam no estágio de submissão também. Percebe-se que estas forças o prejudicaram sobretudo no desempenho de atividades acadêmicas e profissionais. A quietude, a insegurança das falas e a fuga das atividades mais formais do curso reforçam sua dificuldade de avançar em empreendimentos que considera difíceis ou grandiosos. Este comportamento pode exemplificar a crença em uma suposta inferioridade intelectual e incompetência do negro, consequência da naturalização de representações negativas a partir da mentalidade histórico-cultural eurocêntrica. Ao longo da curso, Osei Tutu foi apresentando uma confiança crescente, embora tímida, que culminou na entrega da maioria das atividades no último dia de aula. Significou muito para quem nunca havia entregado nenhuma. Acredito que 
Osei Tutu ainda se encontra no estágio de submissão, ele parece acreditar que suas dificuldades decorrem de fatores internos, de alguma incapacidade de realizar o que é esperado. De acordo com Ferreira (2004), ele estaria em um momento de transformação ou ressocialização, uma estágio em que ocorre a falência das referências raciais anteriores, mas ainda há espanto frente à necessidade de construção de uma nova identidade baseada em novos valores. Talvez, o curso tenha instaurado este estado de vertigem identitário, o que é um avanço de todo modo.

Amina, por sua vez, apresentou o processo de transformação mais abrupto entre aqueles que pareciam partir do estágio de submissão. Inicialmente, o traço mais marcante da relação de Amina com sua identidade racial era a negação da interferência desta variável nos eventos de sua vida, assim como certa preocupação em manter boas maneiras e elegância nos meios mais elitizados onde transitava. Ela não era uma negra qualquer. A conquista do acesso à educação, ao trabalho, ao lazer, neste caso, também à língua inglesa, conduz Amina a se sentir em um lugar mais elevado dentro do seu grupo racial, porém o mesmo não acontece nos locais onde costumava ser a única negra. Fanon (2008) explica que o preto confronta a fragilidade dos conceitos de que se apropria para se destacar entre os seus quando está diante do branco. Sob o olhar do branco, ele não percebe a equiparação de lugares que deseja e, então, sente o peso da melanina. Talvez estar constantemente entre brancos buscando aceitação e valorização tenha contribuído para o complexo de inferioridade de Amina. Seu comportamento pode ser associado ao estágio de submissão quando, primeiro, ela descarta a importância da raça para sua vida, depois quando se afasta das referências do grupo ao qual pertence e incorpora referências do que seria eminentemente valores brancos.

No entanto, ao longo do curso, Amina esboçou um grande deslocamento entre o que parecia uma profunda situação de racismo internalizado para um estágio identitário engajado com a valorização de sua negritude. A mudança de postura apresentada extrapolou a atitude de reconhecer sua identidade negra. Havia uma sensível necessidade de se entregar intensamente ao processo de se tornar negra. As informações que remetiam à África, valores africanos, cultura negra e às questões étnico-raciais se tornaram assuntos caros para Amina, sem contar a forte disposição para combater a discriminação racial que passou a demonstrar. O curso pode ter favorecido não só o desenvolvimento da consciência racial de Amina quanto a emergência de um ativismo frente ao racismo.

Os perfis de Nzinga, Hatshepsut e Nefertiti demonstram que elas já se encontravam em uma situação de pertencimento racial mais articulada. Nzinga narrava suas experiências racializadas com serenidade e consciência. A forma problematizadora com que reagia a investidas racistas para consigo e sua família também traduziam a maturidade adquirida ao longo da vida para lidar com a questão. Como professora de inglês negra e experiente, Nzinga queria aprender a falar de raça e racismo com propriedade em suas aulas, qualificando as iniciativas que já tinha com os fundamentos teóricos que o curso ofereceria. A postura de Nzinga caracteriza um trânsito entre o estágio de militância: estágio em que o indivíduo está familiarizado com aspectos da sua identidade, reconhece os símbolos de branquidade que precisam ser desconstruídos e deseja ampliar conhecimentos sobre sua própria história e cultura; e o estágio de articulação: momento em que já se possui uma concepção mais afrocentrada de mundo, pois o grupo negro se torna a principal referência, e momento no qual se amplia o compromisso com este grupo através do interesse de articular sua negritude com planos de ação em prol do coletivo racial (FERREIRA, 2004).

Hatshepsut parece se encontrar na mesma fase devido ao seu perfil ativista em diferentes instâncias de embate ao sistema e instituições durante a vida. As aulas se tornaram o lugar de compartilhamento de histórias, desabafo, abundavam exemplos das problemáticas que os textos teóricos traziam. Era notória a atitude de apresentar sua bagagem de militância contra a discriminação racial e outras opressões, a fim de afirmar seus valores raciais e estabelecer uma relação de solidariedade com os pares naquele contexto. Marcas contundentes do estágio de militância com um movimento para o estágio de articulação, assinalado tanto na preocupação em contribuir para o processo identitário dos/as colegas (uma função protetora), quanto no objetivo de estender a experiência daquele curso a outros/as professores. Frequentemente, ela reivindicava a ampliação e continuidade do projeto e reclamava do fato de ser uma iniciativa isolada naquela universidade. Diante disso, acredito que o curso contribuiu para fortalecer os mecanismos de articulação de Hatshepsut e aprofundar seu senso de compromisso com o coletivo.

Embora pareça se encontrar entre os estágios de militância e articulação assim como Nzinga e Hatshepsut, Nefertiti aparenta ter um controle maior em relação as suas emoções relativas às questões raciais. Não se percebia traços de hostilidade voltada para pessoas brancas por exemplo, provavelmente o fato de ter trabalhado em cargos de coordenação pedagógica possam ter favorecido este caráter de integrar pessoas diversas, até em posições antagônicas, em prol de um objetivo superior. Esta característica se aproxima do que Ferreira (2004) chama de fase de emersão do 
estágio de militância. Nesta fase, a identidade e a autoestima já se encontram positivadas e a energia pessoal se volta para a reversão da discriminação racial e valores de matriz africana, porém sem radicalismos.

Um traço que indica o avanço de Nefertiti para o estágio identitário de articulação é o firme propósito de consolidar redes de solidariedade na comunidade negra, tanto divulgando iniciativas e empreendimentos de pessoas negras quanto consumindo produtos e serviços desta origem. Ademais, ela evidencia forte determinação para intervir pessoalmente em questões de ordem racial em diversos setores, não apenas no contexto educacional. No curso, ela seguramente adquire ferramentas para vincular o compromisso racial com ações pedagógicas no ensino de inglês e consolida seu ativismo consciente nos espaços formativos em que está envolvida.

Kahina e Cleópatra são mulheres socialmente brancas, isto é, indivíduos cujos traços fenotípicos conduzem à associação dos seus corpos ao grupo étnico-racial branco, o que lhes garante compartilhar os privilégios, benefícios e funções simbólicas atreladas à classe/raça dominante. No início do processo formativo, Kahina se autodeclara parda, os vínculos afetivos e religiosos que traz com a comunidade negra parece impedi-la de perceber que ela não carrega o estigma da cor no seu cotidiano. A título de exemplo, Kahina e Cleópatra não tiveram dificuldade de encontrar imagens de sujeitos/as parecidos/as consigo na mídia, nos livros e nos lugares de poder durante a infância; não costumam ser confundidas com serviçais; não são impedidas de adentrar ou perseguida com desconfiança em lojas ou bancos; dificilmente terão sua competência questionada em razão da sua cor; não sofrem desconforto racial em espaços elitizados por serem as únicas de sua raça, assim como é improvável que sejam interrogadas quanto à origem dos seus bens materiais em qualquer circunstância. Estas são algumas das adversidades comuns à rotina de pessoas negras cuja experiência é desconhecida para quem faz parte da cultura supremacista branca. Entre outros fatores, a isenção destas vivências permite a internalização da superioridade racial, bem como garante mais disposição intelectual e emocional nas relações e interações dentro de sociedades racistas.

Assim, ainda que Kahina queira se posicionar em um lugar racial mais próximo do grupo considerado inferior, ela está fechada na sua brancura, como os negros estão condicionados a sua negrura (FANON, 2004). O acesso ao curso não alterou o pensamento de Kahina quanto a sua identidade social de raça, pelo contrário, a formação intensificou a sua identificação com o grupo racial negro, e ela segue se autodeclarando parda. Mesmo que Kahina reconheça que não experimenta as mazelas do racismo, ela se recusa a ser associada ao grupo responsável por fomentálo. Provavelmente, trata-se de um mecanismo de defesa do ego, melhor descrito por Kilomba (2019), através do qual a negação, a culpa e a vergonha conduzem pessoas brancas a repelirem a sua própria branquitude.

Para Bento (2002), o grupo branco é padrão de referência para espécie humana. A elite garante a retroalimentação desta ideologia do ponto de vista simbólico e material perpetuando desigualdades no âmbito econômico, político e social. Cleópatra parecia consciente disso, especialmente quando se sente desconfortável escutando os relatos de experiências de discriminação dos/das colegas. Ela deve reconhecer que sua cor é uma propriedade que lhe garante vantagens em níveis simbólicos, subjetivos e objetivos, palpáveis mesmo, inclusive do ponto de vista material (CARDOSO, 2010), ainda que se encontre sob o crivo de outras opressões, a exemplo da classe e do gênero.

Sendo a única cursista a se declarar branca, embora tenha se considerado parda por muito tempo, Cleópatra demonstra estar em um processo de desenvolvimento de uma identidade racial branca crítica. Meta complexa umas vez que não há registros de sociedade não racista cuja estrutura e sujeitos/as brancos/as pudessem servir de referência de comportamentos raciais não opressivos. Porém Cleópatra apresentava uma postura racialmente consciente, isto implicava no questionamento constante de seus próprios privilégios em diferentes situações, conforme narrava. Segundo Cardoso (2010), este comprometimento individual diário assentado em crítica e autocrítica contínua pode ser o primeiro passo em direção a minimizar o traço racista de inferiorizar.

Ainda no sentido de atenuar os padrões racistas em que está implicada, há de se considerar a solidariedade de Cleópatra com as realidades raciais de pessoas negras nos lugares em que atua profissionalmente. Ela declarou interesse em contribuir para dinâmicas menos excludentes junto aos estudantes do ensino básico público, tal como evitar atividades que pudessem requerer custo financeiro para execução, elaboração de projetos com temáticas raciais e a constante problematização do conteúdo racista ou não inclusivo dos livros didáticos nas aulas. Possivelmente, as leituras para o desenvolvimento do projeto dentro do campo racial na pós-graduação tenham contribuído para este posicionamento mais analítico de Cleópatra sobre si, sua condição e ações. Igualmente, pode ter sido o elemento motivador para a inscrição no curso do qual tratamos neste artigo. Porém a decisão de alterar o enfoque de sua pesquisa do negro para o branco pode representar mais consciência acerca da sua filiação ao grupo racial branco e às implicações teóricas, práticas e conflitos atrelados a esta identidade. Denota coragem e responsabilidade em 
produzir conhecimento científico no contexto da branquitude, enunciando a partir de um lugar que lhe constitui com fundamentos históricos e sociais indissociáveis da opressão.

Os perfis e análises apresentadas indicam o lugar de tensão em que a dimensão racial se encontra na vida destes/as profissionais. As inquietações, posturas e ideias expressas nas narrativas orais, escritas e atitudes traduzem as implicações da identidade social de raça nas atividades que desenvolvem, na forma com que se relacionam com outras pessoas, nas questões emocionais que carregam e, consequentemente, nas crenças e práticas pedagógicas que desenvolviam. Diante desta constatação, reitero a importância do Letramento Racial Crítico na formação de professores/as de inglês e educadores de modo geral, pois não avisto outra maneira de compreendermos e nos posicionarmos criticamente diante do forte viés ideológico subjacente ao trabalho com as questões étnico-raciais e culturas de matriz africana.

\section{CONSIDERAÇÕES FINAIS}

Parece inegável que a natureza complexa e polêmica inerente ao debate racial junto ao ensino de línguas possa complementar a formação acadêmico-profissional dos/as professores/as, direcionando-os/as à postura críticoreflexiva preconizada pelas abordagens contemporâneas de ensino-aprendizagem de línguas. Quando concretizada, tal formação pode desestabilizar as estruturas e discursos opressivos por meio dos quais as instituições educacionais vêm distorcendo e silenciando as histórias e vivências negras. Simultaneamente, pode incitar estes/as educadores/as a desenvolverem práticas mais interventivas e apresentarem posicionamentos mais politizados em suas aulas. Estas ações constituem o educador preconizado pela Pedagogia Crítica, ou seja, aquele/a engajado/a na emancipação dos estudantes, e comprometido com a afirmação das diferenças e a desconstrução das desigualdades provenientes delas. Em suma, um/a sujeito/a consciente do seu papel em prol da educação para a cidadania.

A experiência do curso de extensão sobre raça e africanidades no ensino de inglês não só ofereceu base teórica para os/as professores/as abordarem as questões étnico-raciais em suas aulas, como aguçou sua percepção para os eventos cotidianos de racismo que assistiam, escutavam ou participavam. A cada aula, avolumavam-se os relatos indignados das diversas situações que se tornavam incômodas como pouco ou nunca haviam experimentado. Além de se mostrarem gradativamente mais motivados a continuarem estudando os textos teóricos apresentados e outros, os/as cursistas pareciam mais sensíveis às opressões vividas por si e pelos/as outros/as.

O processo de formação, histórias e análises descritas neste artigo evidenciou que se engajar na promoção de valores positivos da comunidade negra requer a mobilização de crenças diretamente associadas à identidade social de raça dos indivíduos. Conforme indica a Teoria Racial Crítica, o racismo opera em toda parte, e na maioria das relações sociais. Diante disso, o papel de educadores/as dispostos a promoverem justiça social não deve se encerrar na constatação do racismo. As proposições do Letramento Racial Crítico marcam a importância de interrogarmos discursos e comportamentos, além de empreendermos ações antirracistas em todos os ambientes em que atuarmos. $\mathrm{Na}$ escola, por exemplo, temos ainda que incentivar a ruptura de silêncios e a recusa da neutralidade do currículo, do material didático, dos/as colegas de trabalho e gestores/as. O propósito maior é favorecer debates que conduzam todos e todas a engajarem-se pessoalmente na luta contra o racismo, incluindo o racismo existente em si próprios/as.

\section{REFERÊNCIAS}

ALMEIDA, S. (2019). Racismo Estrutural. São Paulo: Editora Pólen.

BENTO, M. A. S. (2002). Branqueamento e branquitude no Brasil. In: CARONE, I.; BENTO, M. A. S. (Org.). Psicologia social do racismo: estudos sobre branquitude e branqueamento no Brasil. Petrópolis: Vozes.

BRASIL, M. E. (2003). Lei n. ${ }^{\circ}$ 10639, de 09 de janeiro de 2003. Altera a Lei no 9.394, de 20 de dezembro de 1996, que estabelece as diretrizes e bases da educação nacional, para incluir no currículo oficial da Rede de Ensino a obrigatoriedade da temática "História e Cultura Afro-Brasileira", e dá outras providências. Diário Oficial [da] República Federativa do Brasil. Brasília, DF. 9 jan. 2003 Disponível em: <http://www. planalto. gov.br/ccivil_03/Leis/2003/L10.639.htm > Acesso em: 30 set. 2020. 
BRASIL, M.E. (2004). Parecer do Conselho Nacional de Educação n. ${ }^{\circ} 3$ (CNE03/2004). Dispõe sobre as Diretrizes Curriculares Nacionais para a Educação das Relações Étnico-raciais e para o Ensino de História e Cultura Afro-Brasileira e Africana. 10 mar. 2004 Disponível em: < http://portal.mec.gov.br/dmdocuments/cnecp_003.pdf> Acesso em: 10 Out. 2020.

BRASIL, M. E. (2004). Resolução n. ${ }^{0}$ 1, de 17 de junbo de 2004. Institui Diretrizes Curriculares Nacionais para a Educação das Relações Étnico-raciais e para o Ensino de História e Cultura Afro-Brasileira e Africana. 17 Jun. 2004 Disponível em: http://portal. mec.gov.br/cne/arquivos/pdf/res012004.pdf Acesso em: 10 Out. 2020.

CARDOSO, L. Branquitude acrítica e crítica: supremacia racial e o branco anti-racista. 1 Jun. 2010. Disponível em: < art. LourencoCardoso.pdf (clacso.edu.ar) > Acesso em: 5 Dez. 2020.

CARR, W.; KEMMIS, S. (1998). Teoria crítica de la enseñanza. Barcelona: Martins Roca.

CRENSHAW. K. (1991). Mapping the Margins: intersectionality, identity politics, and violence against Women of Color, 11 Jul. 1991. Disponível em : < https://www.racialequit ytools.org/resourcefiles/mapping-margins.pdf> Acesso em: 15 Out. 2020 .

D’ADESKY, J. (2005). Pluralismo étnico e multiculturalismo: racismo e antirracismos no Brasil. Rio de Janeiro: Pallas.

ELLIOT, J. (1989). Educational theory and the professional learning of teachers: an overview. Cambridge journal of education v.19, n. 1, p. 82-101.

FANON, F. (2008). Pele negra, máscaras brancas. Salvador: EDUFBA

FREIRE, P. (1996). Pedagogia da autonomia: saberes necessários à prática educativa. São Paulo: Paz e Terra.

GILROY, Paul. (2001). O Atlântico negro: modernidade e dupla consciência. São Paulo: Ed.43.

GRIMMETT, P. (1998). Introduction. In: GRIMMETT, P.P.; ERICKSON, G.L. (Org.) Reflection in teacher education. New York: Teachers College Press.

RAJAGOPALAN, K. (2003). Por uma linguística crítica: linguagem, identidade e a questão ética. São Paulo: Parábola Editorial.

FERREIRA, A. J. (2006) Formação de professores Raça/etnia: reflexões e sugestões de materiais de ensino. Cascavel: Coluna do Saber.

FERREIRA, A. J. (2015). Letramento racial crítico através de narrativas autobiográficas: com atividades reflexivas. Ponta Grossa: Estúdio Texto.

FERREIRA, R. F. (2004). Afro descendente: identidade em construção, São Paulo: EDUC; Rio de Janeiro: Pallas.

HOOKS, B. Teaching critical thinking: practical wisdom. New York/London: Routledge, 2010.

LADSON-BILLINGS, G. (2006). Race and TESOL: introduction to concepts and theory. Cambridge University Press, p.471-489.

LADSON-BILLINGS, G. (2009). Just what is critical race theory and what's it doing in a nice field like education? In: TAYLOR, Ed.; LADSON-BILLINGS, G.; GILLBORN, D. Foundations of Critical Race Theory in Education. New York: Routledge, p.17-36.

MOITA LOPES, L. P. (1996) Oficina de linguística aplicada: a natureza social e educacional dos processos de ensino e aprendizagem. Campinas, SP: Mercado de Letras,

PENNYCOOK, A. (1994). The Cultural Politics of English as an International Language. London: Longman.

RAJAGOPALAN, K. (2003). Por uma linguística crítica: linguagem, identidade e a questão ética. São Paulo: Parábola Editorial.

SILVA, A. C. (2001). Desconstruindo a discriminação do negro no livro didático. Salvador: EDUFBA. 
SOLORZANO, D. G.; YOSSO T. J. (2005). Critical Race Methodology: counter-storytelling as analytical framework for educational research. In: In: TAYLOR, E.; LADSON-BILLINGS, G.; GILLBORN, D. (Ed.) Foundations of Critical Race Theory in Education. New York: Routledge, p.131-147.

THIOLLENT, M. (19b6). Metodologia da pesquisa-ação. São Paulo: Cortez: Autores Associados.

TRIPP, D. (2005). Pesquisa-ação: uma introdução metodológica. Educação e Pesquisa, São Paulo, v. 31, n.3, p. 443-466.

Recebido: 3/11/2020

Aceito: $3 / 3 / 2021$

Publicado: 22/3/2021 